\title{
Communication and Education: Effects of Parental Influences on a Child's Career Choice
}

\author{
Mark Cistulli, Jason L. Snyder
}

Central Connecticut State University, New Britain, CT, USA

Objectives: Myriad options exist when pursuing a career, including corporate, nonprofit, education, and military service. The life-altering nature of these decisions can elicit distress, which is why discussions with parents about the fields the young adults are considering is so important. Therefore, this study looks specifically at the influence of parents' attitudes toward the military and past military service on their a) willingness to engage their recruitment-aged children in discussion about enlistment, and b) use of comforting behaviors when talking about enlistment with their recruitment-age children.

Methods: An online survey of 275 U.S. citizens with at least one child between the ages of 17 and 25 was conducted. Respondents ranged in age from 32 to 63 years old (Mean $=43.9)$ with $53(19.3 \%)$ reporting having served in the military. This survey also collected data on the following variables: overall impression of the U.S. military, enlistment discussion, and use of comforting behaviors.

Results: Two research questions and two hypotheses were tested using Pearson correlation coefficient analysis and multiple regression analysis. Results demonstrate that parents' attitudes toward an organization - in this case the United States military - would affect how they choose to communicate about career choices with their children.

Conclusions: Organizations should pay attention to these results as companies engage in a global competition for talent. Individual, independent decision making is often viewed as a common influencer of career choice. However, this study demonstrates that parents can have a significant impact on career choice.

Key Words: Careers, Education Communication, Military Advertising, Parent-Child Communication, Attitude toward Brand

\section{Introduction}

Young adults must wrestle with major future career decisions. For many individuals, there are many options in life when pur-

Received: Apr 4, 2018 Revised: Jul 10, 2018 Accepted: Jul 13, 2018 Corresponding author: Jason L. Snyder

Central Connecticut State University, 1615 Stanley Street, New Britain, CT 06050, USA

Tel: +1-860-832-3207, E-mail: snyderjal@ccsu.edu

This is an Open Access article distributed under the terms of the Creative Commons Attribution Non-Commercial License (http://creativecommons.org/licenses/ by-nc/4.0/) which permits unrestricted non-commercial use, distribution, and reproduction in any medium, provided the original work is properly cited.

Copyright $\odot 2018$ Korean Association for Business Communication. suing a career, including corporate, nonprofit, education, and, in many cases, military service, which is why discussions with parents about the organizations young adults are considering is so important. Parents are the most important influence on children even when their perceived authority over their children begins to disappear (Collins, Maccoby, Steniberg, Hetherton, \& Bornstein, 2000). Although young people do not always conform to their parents' advice about career paths, they still lean on their parents for guidance (Collins \& Luebker, 1994). In addition to guidance, parent-child communication can play a stress-relieving role for the child while they wrestle with career choices. In fact, research has demonstrated that a young person's 
ability to freely communicate with his or her parent can help alleviate stress and feelings of loneliness associated with difficult decisions (Marta, 1997). Therefore, it is important for us to better understand the nature of parent-child communication in the process of making career choices.

Research has established a connection between parents' previous military service and their likelihood of participating in an enlistment discussion (Cistulli, Snyder, \& Jacobs, 2012). The relationship between parents' previous military service and comforting has not yet been explored. This study explores parents' use of comforting behaviors when talking with their children about the stressful decision to pursue a career in the military. Parents' history with the military may influence their use of communication tactics when talking with their children about a career in the military. Specifically, this study evaluates the influence of parents' attitudes toward the military and past military service on their a) willingness to engage their recruitment-aged children in discussion about enlistment and b) use of comforting behaviors when talking about enlistment with their recruitment-age children.

\section{Comforting Behaviors}

Comforting behaviors are a form of compassionate communication that include "communicative attempts to alleviate the emotional distress of another" (Burleson \& Goldsmith, 1998, p. 246). Five types of comforting behaviors ameliorate distress - an other orientation, refraining from general negativity, relating, problem solving, and a different perspective (Bippus, 2001). Those who use an "other" orientation focus communication on the other's feelings and demonstrate caring for the distressed other. When refraining from general negativity, people avoid saying things that upset the distressed other. The relating dimension includes behaviors designed to help distressed people see that the comforter can understand and relate to the problem. In Forbus and Snyder's (2013) organizational communication research, they said that in the relating dimension, the comforter also helps people see that their problems are not unique. Comforters who use the problem solving dimension help distressed people generate solutions to their problems. The different perspective dimension comprises comments that help distressed people reappraise the situation they are in and get them to see the situation in a new way. Parents have the option of using any or all of these forms of comforting communication when talking with their children about the decision to pursue a career in the military. The present study wants to know if parents' attitudes and past military service predict their choice of comforting communication.
Attitude toward the Military Brand and the Intent to Discuss Enlistment

Previous research has shown that attitude toward the military brand can act as proxy for brand attitude and can, in turn, impact some behaviors, such as enlistment discussion, which is a family member's intention to talk about enlisting in the military (Cistulli, Jacobs, \& Snyder, 2015; Cistulli, et al., 2012). Discussions regarding attitudes, intentions, and behavior often begin with Fishbein and Ajzen's (1975) Theory of Reasoned Action. They suggested that the potential cause of behavior is one's intention to engage in that behavior. Attitudes influence intention, and intention, in turn, leads to behavior. This theory assumes that people form their intentions by considering the outcomes of their behavior and relevant subjective norms-the perceptions of others' evaluation of a behavior. Attitude toward the brand is generally regarded as an evaluation of particular brand attributes-those attributes can be evaluated either positively or negatively (Ajzen \& Fishbein, 1980). Ajzen (1989) expanded on this theory by introducing a variable that measures how easy or difficult it is to perform a behavior-perceived behavioral control. Others, such as Warshaw, Sheppard and Hartwick (1983), have posited that the process of trying includes the physical and mental processes that exist between intention and the attainment of some previously set goal. Mackenzie, Lutz, and Belch (1986) have shown that shaping consumers' attitudes toward a brand is an important way to understand their behavior. When measuring attitude toward the ad, attitude toward the brand, and purchase intent, Ang and Low (2000) found that ads perceived as good, creative ads were often evaluated more favorably and enhanced perceptions (though less than attitude toward the ad) for brand attitude and purchase intention. There is clearly a great deal of research on the influence of attitude, intention, and behaviors in organizational contexts. This study will consider these relationships through the hypotheses and research questions below.

As stated above, research has demonstrated a link between attitude toward the military and willingness to participate in an enlistment discussion. Prior attitudes can trigger communicative behavior. Therefore, this study tries to replicate those findings and also look at the relationship between attitudes and comforting behaviors. Research has not yet demonstrated a link between attitudes and comforting behaviors. Therefore, this study explores the potential connections between attitude and comforting behaviors. In particular, it examines how parents' attitudes toward the military will influence their use of comforting behaviors when talking with their recruitment-aged children about military enlistment. One could argue that positive evaluations of the military will lead to a greater use of com- 
forting, as the parent may be favorably disposed toward helping the child come to grips with an enlistment decision. Conversely, parents who have negative attitudes toward the military may be less likely to use comforting behaviors during these discussions. They may feel that alleviating stress would lead to a greater likelihood of the child choosing enlistment. Parents who have negative attitudes toward the military would not likely want their children choosing enlistment. Studies in other career fields indicate similar patterns of parental influence (Archer, Dewitt, \& Osborne, 2015; Dietrich \& Kracke, 2009; Hoffman, Hofacker, \& Goldsmith, 1992; Shellenbarger, 2006).

\section{Methods}

\section{Research Questions and Hypotheses}

In the present study, the following research questions and hypotheses below are put forth. The research questions are stated as questions due to a lack of prior research into the influence of comforting behaviors on the outcomes. The hypotheses are related to one another because they both involve the outcome of enlistment discussion.

- Research Question 1: Which comforting behaviors are predicted by parents' attitude toward the military?

- Research Question 2: Which comforting behaviors are predicted by parents' previous military service?

- Hypothesis 1: Parents' attitude toward the military (MilAtt) increases the likelihood of enlistment discussion.

- Hypothesis 2: Parents' previous military service increases the likelihood of enlistment discussion.

\section{Participants}

Participants $(N=275)$ included 150 men $(54.5 \%)$ and 125 women $(45.5 \%)$. The majority of the participants were White $(N=207,75.3 \%)$, but $8.7 \%(N=24)$ of participants were Black, 3.6\% $(N=10)$ were Latino/a, and 9.5\% $(N=26)$ were Asian/ Pacific Islander. The participants ranged in age from 32 to $63(M$ $=43.92, S D=7.10)$ and identified their political affiliation as Democrat $(N=100,36.5 \%)$, Republican $(N=84,30.7 \%)$, Independent $(N=81,29.6 \%)$, or Not Registered $(N=9,3.3 \%)$. Age remains important, in part, because previous research showed that older people have more positive attitudes toward the military (Cistulli et al., 2012). To assess previous military service, we asked the following question: "Have you ever served in a branch of the U.S. military?" In response to that question, 220 (80.0\%) participants said no, and 53 (19.3\%) participants said yes.

\section{Data Collection}

U.S. citizens with at least one child old enough to be recruited by the United States military completed an online survey using Amazon's Mechanical Turk (M-Turk) tool (https://www.mturk. com/mturk/welcome). This tool provides people the opportunity to complete human intelligence tasks (HITs) for compensation. The survey acted as a HIT, and the participants chose whether to complete the survey.

Once participants selected our survey in M-Turk, they were directed to a website that included the study's information sheet. If they agreed to continue in the study, they were asked if they were U.S. citizens and if they have at least one child between the ages of 17 and 25. If they answered yes to both questions, they were directed to another webpage that included the survey for this study. After completing the survey, participants were thanked for their participation. Participants were paid $\$ .50$ for completing the survey.

\section{Analysis}

Participants rated their attitude toward the military using a fivepoint semantic differential derived from Donthu (1998). The six reliable items ( $\alpha=.91$ ) were as follows: unappealing/appealing, unbelievable/believable, unimpressive/impressive, unattractive/ attractive, unexciting/exciting, and not likeable/likeable. To derive a score on this measure, we computed the average $(M)$ and standard deviation $(S D)$ for the six items $(M=3.87, S D=.88)$.

Participants answered three questions about discussing enlistment in the United States military. The questions $(\alpha=.83)$ were: "I would discuss with my child his or her options for enlisting in the U.S. military", "To learn more about the U.S. military, I would encourage my child to visit a recruiter before making a decision about enlisting in the U.S. military", and "I am likely to recommend that my child consult recruiting materials about the U.S. military." Participants indicated their willingness to participate in these behaviors by responding to a fivepoint Likert-type scale ranging from 1 (very unlikely) to 5 (very likely). We computed an average of the three items to arrive at a score for enlistment discussion $(M=3.63, S D=1.09)$.

The comforting scale comprises five specific behaviors that are particularly effective in alleviating others' distress (Bippus, 2001). Forbus and Snyder (2013) successfully modified the items to fit a social marketing context. We modified the items to fit this branding context. The items are scored on a Likert-type scale ranging from 1 (strongly disagree) to 5 (strongly agree).

The first behavior, other orientation, was assessed using the following items: "I will stay centered on my child's thoughts and feelings," "I will reveal my concern," "I will focus on my child's thoughts and feelings." These 3 items yielded an acceptable reliability $(\alpha=75)$. To arrive at an other orientation score, we calculated a mathematical average of the items $(M=4.38, S D=.49)$. 
The second behavior, refraining from negativity, was assessed using the following items $(\alpha=.69)$ : "I will judge my child's decision," "I will not show support for my child's decision," "I will make my child feel accepted," "I will come off as indifferent about my child's decision." We calculated an average of these items. The higher the score on this dimension, the more the parent refrained from negativity $(M=3.38, S D=.55)$.

The third behavior, relating, was assessed using the following, reliable items $(r=.64)$ : "I will show my child that I can relate to his or her situation," "I will let my child know that I have faced similar issues." We calculated an average of the two items $(M=$ $4.06, S D=.79$ ).

The fourth behavior, problem solving, was assessed using the following items: "I will be helpful in coming up with solutions to my child's enlistment decision," "I will help my child make an enlistment decision," "I will provide good advice," "I will tell my child what he or she can do to make an enlistment decision." These items were reliable ( $\alpha=.75)$. Again, we calculated a mathematical average of the items $(M=4.26, S D=.63)$.

The final comforting behavior, different perspective, was assessed using the following items: "I will help my child step back and look at his or her feelings in a different light," "I will help my child change his or her perspective on enlisting." The alpha coefficient was unacceptably low for these items $(\alpha=.53)$. Therefore, this dimension was dropped from further analysis.

\section{Results}

To review the relationships among the variables of interest, Pearson correlation coefficients among the following variables were run: attitude toward the military, previous service, age, gender, other orientation, refraining from negativity, relating, problem solving, perspective taking, and enlistment discussion.
In order to make this analysis feasible, the advice of Cohen, Cohen, West, and Aiken (2003) was followed to create dummy codes for the variables of previous service and gender. Previous service was coded such that $0=$ No and $1=$ Yes. Gender was coded such that $0=$ Male and $1=$ Female. These dummy codes made it possible to include gender and previous service in the Pearson correlations coefficient analysis as well as the analyses that were conducted using multiple regression analysis. The results of the Pearson correlation coefficient analysis are provided in Table 1.

The results in Table 1 indicate that other orientation is significantly related to nearly all of the variables in the table. It is not only related to the other factors of comforting, but it is also related to parents' attitude toward the military, parents' military service, as well as parents' age and gender. Additionally, parents with military experience are more likely to discuss enlistment as well as use other orientation, refrain from negativity, and relating comforting behaviors. Women are more likely to employ other orientation but less likely to refrain from negativity. Finally, parents who are more willing to participate in enlistment discussion have better attitudes toward the military, more likely to have military experience, and also more likely to employ all of the comforting behaviors except for refraining from negativity.

To address the research questions regarding comforting behaviors, a series of regressions were run. Research question one asked which comforting behaviors were predicted by attitude toward the military. Research question two asked which comforting behaviors were predicted by parents' previous military service. To explore these questions, we regressed, in separate models, each of the four dimensions of comforting behaviors onto the following independent variables: attitude toward the military, parents' previous service, age, and gender (see Table 2). As stated previously, the perspective taking dimension of com-

Table 1. Correlations among variables of interest

\begin{tabular}{|c|c|c|c|c|c|c|c|c|}
\hline Variable & Serve & Age & Gender & Orient & Refrain & Relate & Solve & EnlistDiscuss \\
\hline MilAtt & $.13^{*}$ & .12 & -.04 & $.20^{* *}$ & -.05 & $.25^{* *}$ & $.26^{* *}$ & $.64^{* *}$ \\
\hline Serve & & -.02 & $-.27^{* * *}$ & $-.12^{* *}$ & $.15^{* *}$ & $.20^{* *}$ & -.00 & $.14^{*}$ \\
\hline Age & & & .05 & $.17^{* *}$ & -.02 & .06 & $.16^{* *}$ & .10 \\
\hline Gender & & & & $.18^{* *}$ & $-.14^{*}$ & -.05 & .07 & -.01 \\
\hline Orient & & & & & -.03 & $.41^{* *}$ & $.57^{* *}$ & $.24^{* *}$ \\
\hline Refrain & & & & & & .09 & .07 & -.09 \\
\hline Relate & & & & & & & $.50^{* *}$ & $.26^{* *}$ \\
\hline Solve & & & & & & & & $.27^{* *}$ \\
\hline
\end{tabular}

Note. MilAtt = parents' attitude toward the military; Serve $=$ previous military service $(0=$ no service, $1=$ past service); gender $(0=$ male, $1=$ female); Orient $=$ other orientation; Refrain = refraining from negativity; Relate = relating; Solve = problem solving; EnlistDiscuss = enlistment discussion. ${ }^{*} p<.05 .{ }^{* *} p<.01$. Two tailed. 
forting was not included in any analysis because of its insufficiently low alpha reliability coefficient.

In the first regression equation, other orientation was included as the dependent variable. Attitude toward the military was a significant predictor in the model $(\beta=.22, p<.001)$. Parents with positive attitudes toward the military were more likely to employ an other orientation than parents with negative attitudes toward the military. Although parents' previous military service was not a significant predictor of other orientation $(\beta=$ $-.11, p=.07)$, it was approaching significance. Although not hypothesized, it is also worth noting that women were more likely to use other orientation than men. This gender difference will be discussed in greater detail in the Future Research and Limitations section below.

In the second regression equation, refraining from negativity was included as the dependent variable. In this model, attitude toward the military was not significant $(\beta=-.08, p=.17)$, but parents' previous military service was significant $(\beta=.18, p<$ .001). Parents who had previous military service were more likely than parents with no military service to report refraining from negativity when comforting their child. Again, the results yielded a gender difference. Women were less likely to refrain from negativity than men. We will address gender differences in the Future Research and Limitations section below.

The third regression demonstrated that both parents' attitudes toward the military $(\beta=.23, p<.001)$ and previous military service $(\beta=.19, p=.002)$ were significant predictors of the relating dimension of comforting.

The final regression included problem solving as a dependent variable. In that model, attitude toward the military $(\beta=.27, p<$ .001) was a significant predictor while parents' previous military service was not $(\beta=.01, p=.88)$. Parents who reported a positive attitude toward the military were more likely to engage in problem solving when comforting their children, compared to parents who held negative attitudes toward the military.

In order to test hypotheses one and two, a regression of enlistment discussion on the following independent variables was run: parents' attitude toward the military, parents' previous military service, age, gender. The regression equation was significant $(F[4,268]=44.28, p<.001)$ and accounted for $40 \%$ of the variance in enlistment discussion.

Hypothesis one stated that a more positive attitude toward the military would lead to a higher probability of enlistment discussion. When considered on its own, parents' attitude toward

Table 2. Comforting behaviors regressed onto independent variables of interest

\begin{tabular}{|c|c|c|c|c|}
\hline Variable & Beta coefficient & Standard error & Standardized beta $(\beta)$ & $P$ value \\
\hline \multicolumn{5}{|c|}{ Dependent variable: Other orientation $\left(F[4,268]=5.04, p=.001, R^{2}=.07\right)$} \\
\hline MilAtt & .12 & .03 & .22 & $<.001$ \\
\hline Serve & -.13 & .08 & -.11 & .080 \\
\hline Age & .00 & .00 & .00 & 1.000 \\
\hline Gender & .11 & .06 & .11 & .070 \\
\hline \multicolumn{5}{|c|}{ Dependent variable: Refraining from negativity $\left(F[4,268]=4.63, p=.001, R^{2}=.07\right)$} \\
\hline MilAtt & -.05 & .04 & -.08 & .170 \\
\hline Serve & .25 & .09 & .18 & .005 \\
\hline Age & .00 & .01 & .01 & .880 \\
\hline Gender & -.15 & .07 & -.14 & .030 \\
\hline \multicolumn{5}{|c|}{ Dependent variable: Relating $\left(F[4,268]=8.63, p<.001, R^{2}=.11\right)$} \\
\hline MilAtt & .20 & .05 & .23 & $<.001$ \\
\hline Serve & .37 & .12 & .19 & .002 \\
\hline Age & -.01 & .01 & -.09 & .120 \\
\hline Gender & -.12 & .09 & -.07 & .220 \\
\hline \multicolumn{5}{|c|}{ Dependent variable: Problem solving $\left(F[4,268]=5.35, p<.001, R^{2}=.07\right)$} \\
\hline MilAtt & .19 & .04 & .27 & $<.001$ \\
\hline Serve & .01 & .10 & .01 & .880 \\
\hline Age & .00 & .01 & .00 & .980 \\
\hline Gender & -.00 & .08 & -.00 & .960 \\
\hline
\end{tabular}

Note. MilAtt = parents' attitude toward the military; Serve = previous military service ( $0=$ no service, $1=$ past service); Gender $(0=$ male, $1=$ female). 
the military was related to enlistment discussion $(r=.64, p<$ $.01)$. When considered in the larger picture provided by regression analysis, parents' attitude toward the military was a statistically significant, positive predictor of enlistment discussion ( $\beta$ $=.62, p<.001)$. Those parents who reported a more positive attitude toward the military also reported a greater willingness to engage in an enlistment discussion with their recruitment-aged child. Therefore, hypothesis one was supported by the data.

Hypothesis two stated that previous service would also positively predict more enlistment discussion. Although the correlation between enlistment discussion and parents' previous military service was significant $(r=.14, p<.05)$, the standardized Beta coefficient was not significant when considered in this regression model $(\beta=.06, p=.24)$. Therefore, hypothesis two was not supported by the data. None of the remaining independent variables in the model reached statistical significance.

\section{Discussion}

In response to research question one, the data offered support for the notion that parents' attitudes toward the military predict their use of comforting behaviors. Those attitudes do predict use of other orientation, relating, and problem solving, but not refraining from negativity. The data also provided some support for research question two, which was related to the relationship between parents' previous military service and their use of comforting behaviors. Previous military service does predict refraining from negativity and relating. It does not, however, predict either other orientation or problem solving.

When testing hypothesis one and two, the decision was made to conduct a regression analysis with the two predictors in hypothesis one and hypothesis two along with the other listed variables, because, as discussed above, the literature suggests that all of these variables influence the outcome of the enlistment discussion. Therefore, a Pearson correlation coefficient illustrates the nature of the relationship between the predictors and the outcome variable. It does not, however, provide the more complete picture provided by regression analysis of the unique impact of each predictor.

To some degree, previous research showed that attitudes toward the military and previous military service would impact behavioral intentions, such as enlistment discussion (Cistulli et al., 2012). That research demonstrated that attitudes toward the military and previous military service would affect parents' willingness to discuss enlistment with their children. Unlike this study, that research did not explore the nature of those interactions. In line with the existing literature, this study did show that attitude toward the military predicts enlistment discussion, further strengthening the attitude-behavioral intention-behavior relationship (Ajzen \& Fishbein, 1980; Ang \& Low, 2000; Fishbein \& Ajzen, 1975). Future research may reveal a similar pattern of relationships in other organizational contexts. Although these results are useful for the military, other organizations should pay attention to these results as companies engage in a global competition for talent.

When it comes to comforting behaviors, the only one predicted by both attitude toward the military and previous service is relating. In both cases, parents reported being more likely to exhibit behaviors such as letting the child know they have faced similar situations and can relate to the child's present situation. For parents who have not served, they are less likely to use relating because they cannot, in many cases, understand wrestling with that decision. People who have a negative attitude of the military report not using relating. This could be because their negative beliefs meant that they never seriously considered enlistment themselves. Therefore, they cannot relate at all. The past research (Forbus \& Snyder, 2013) concluded that individuals who use the relating dimension help distressed others find solutions to the problems causing their distress. The present findings may be in line with that past research. Parents with no military service and low attitude toward the military may not be able to relate and help develop different solutions because this particular option is foreign to their worldview.

Previous military service positively predicted refraining from negativity. Those parents who had served in the military were more likely to stay positive and refrain from expressing negative attitudes toward their child's potential decision to serve. One reason this may occur is that parents may find it hard to frame the decision to join the military negatively when they had served themselves. In line with previous research in this area, these parents may be trying to avoid cognitive dissonance (Cistulli et al., 2012; Festinger, 1957). To be negative about this decision would reflect badly on their own choices. Thus, in an effort to avoid cognitive dissonance, parents may try to avoid being negative when talking about enlistment with their child.

It thus appears that attitude, specifically, attitude toward the military, is the driving force in these results. Attitudes can predict behaviors - this notion is consistent with previous literature. What makes this study interesting is the revelation that people with negative attitudes are less likely to discuss enlistment and less likely to offer comfort to their children when discussing enlistment. People with positive attitudes will offer more comfort than people who hold negative attitudes. In fact, people who are negative are less likely to offer any comfort to their children. They do not want to frame the decision positively or make their children feel at ease about enlisting in the military. 


\section{Implications}

In many cultures, it is commonly believed that children make their own career choices. However, a number of influencers have an impact on those types of decisions. The present study demonstrated that parents influence career choices. The present study explored the role of parental attitudes and communication behaviors on their child or children's decision to enlist in the United States Military. Military enlistment in the United States is voluntary. Individuals may choose a military career in the United States in the same way they may choose any other career path. However, in countries with conscription (i.e., mandatory military service), such as Israel and South Korea, service in the military is generally not a choice. For parents and practitioners in countries with conscription, the results of this study may be applied to career choices, not just military service.

\section{Future Research and Limitations}

There is fertile ground for future research based on the results of this study. Certainly, future research could explore the impact both the parents' and child's gender may have on discussing the military. This could be explored more fully when considering country of origin. For example, a mother in the United States may have certain expectations for her son or daughter's career - including the option of a career in the military. However, in conscription countries, those expectations might be considerably different.

Additionally, culture, in and of itself, might also impact these results. This is a limitation of this research. While the study covers the United States, a major player in international business and communication as well as a large and ethnically and racially diverse country, the next study should consider and compare countries from all regions of the world.

In the present study, gender differences were uncovered and are worthy of discussion here. First, women are less likely to refrain from negativity and more likely to focus on their child's feelings. They are more likely than men to let their children know that they do not approve of the decision if they disagree with it. Perhaps this behavior is because of the many instances in which women have had negative experiences in the military - two more recent and well-known events would be the Tailhook Symposium "scandal" and "secret" Marine Facebook group exploitation as well as the ongoing discussion of women serving in combat. Additionally, it would be interesting to also look at the gender of the children as well as those of the parents. These details could create a different dynamic in terms of a potential enlistment discussion.

Despite some interesting findings, there are limitations to this research. The first is unequal cell sizes. While both cells were ad- equate to examine the data, more equal cell sizes are desirable. The second is the alpha reliability for the comforting behavior, different perspective. The reliability was less than acceptable, which is the reason it was dropped from the analysis.

An interesting point not covered in this study and a potential for future research is the notion of who initially initiated the conversation between parent and child. This study found that parents' previous military service did not predict enlistment discussion. Do parents respond differently when the child initiates the discussion? Will the child's gender change the nature of the parent's use of comforting behaviors? This study does not hold the answer to these questions, but the questions are worth further investigation.

\section{Conclusion}

The present study took the first steps toward examining the impact of parents' attitudes toward the military and previous military service on their career-choice communication with their children. The results suggest that attitude toward the military and previous military service can impact compassion comforting behaviors - between family members. The results showed that a parent's perceived positive attitude toward the military would impact their other orientation, relating, and problem solving. It should be of little surprise that their attitudes toward an organization, in this case the military, would affect how they choose to communicate with their children about this and other potentially important career decisions.

\section{References}

Ang, S. H., \& Low, S. Y. M. (2000). Exploring the dimensions of ad creativity. Psychology and Marketing, 17(10), 835-854.

Ajzen, I. (1989). Attitude structure and behavior. In A. R. Pratkanis, S. J. Breckler, \& A. G. Greenwald (Eds.), Attitude structure and function (pp. 241-274). Hillsdale, NJ: Lawrence Erlbaum Associates.

Ajzen, I., \& Fishbein, M. (1980). Understanding attitudes and predicting social behavior. Englewood Cliffs, NJ: Prentice-Hall.

Archer, L., Dewitt, J., \& Osborne, J. (2015). Is science for us? Black students' and parents' views of science and science careers. Science Education, 99(2), 199-237.

Bippus, A. M. (2001). Recipients' criteria for evaluating the skillfulness of comforting communication and the outcomes of comforting interactions. Communication Monographs, 68(3), 301-313.

Burleson, B. R., \& Goldsmith, D. J. (1998). How the comforting process works: Alleviating emotional distress through conversationally induced reappraisals. In P. A. Anderson \& L. K. Guerrero 
(Eds.), Handbook of communication and emotion: Research, theory, applications, and contexts (pp. 245-280). New York, NY: Academic Press.

Clark, C. (1997). Misery and company: Sympathy in everyday life. Chicago, IL: University of Chicago Press.

Clark, R. D., \& Shields, G. (1997). Family communication and delinquency. Adolescence, 32(125), 81-92.

Cohen, J., Cohen, P., West, S. G., \& Aiken, L. S. (2003). Applied multiple regression/correlation analysis for the behavioral sciences. New York, NY: Routledge.

Collins, W. A. (1995). Relationships and development: Family adaptation to individual change. In S. Shulman (Ed.), Close relationships and socioemotional development. (pp. 128-154). New York, NY: Ablex.

Collins, W. A., \& Luebker, C. (1994). Parent and adolescent expectancies: Individual and relational significance. New Directions for Child and Adolescent Development, 1994(66), 65-80.

Collins, W. A., Maccoby, E. E., Steinberg, L., Hetherington, E. M., \& Bornstein, M. H. (2000). Contemporary research on parenting: The case for nature and nurture. American Psychologist, 55(2), 218-232.

Cistulli, M., Jacobs, R., \& Snyder, J. (2015). Global force for branding: A study of attitudes, intentions, the military, and the wars overseas. Journal of Promotion Management, 21(2), 190-207.

Cistulli, M. D., Snyder, J. L., \& Jacobs, R. (2012). Affective organizational commitment as a predictor of military discussion and recommendation. International Journal of Business, Humanities and Technology, 2(3), 27-33.

Dietrich, J., \& Kracke, B. (2009). Career-specific parental behaviors in adolescents' development. Journal of Vocational Behavior, 75(2), 109-119.

Donthu, N. (1998). A cross-country investigation of recall and attitude toward comparative advertising. Journal of Advertising, 27(2), 111-122.

Festinger, L. (1957). A theory of cognitive dissonance. Stanford, CA: Stanford University Press.

Fishbein, M., \& Ajzen, I. (1975). Belief, attitude, intention and behavior: An introduction to theory and research. Reading, MA: Addison-Wesley.

Forbus, R., \& Snyder, J. L. (2013). Use of comforting to enhance so- cial marketing success: A case study. Social Marketing Quarterly, 19(2), 97-109.

Frost, P. J., Dutton, J. E., Worline, M. C., \& Wilson, A. (2000). Narratives of compassion in organizations. In S. Fineman (Ed.), Emotion in organizations (2nd ed., pp. 25-45). Thousand Oaks, CA: Sage.

Hoffman, J., Hofacker, C., \& Goldsmith, E. B. (1992). How closeness affects parental influence on business college students' career choices. Journal of Career Development, 19(1), 65-73.

Kanov, J. M., Maitlis, S., Worline, M. C., Dutton, J. E., Frost, P. J., \& Lilius, J. M. (2004). Compassion in organizational life. The American Behavioral Scientist, 47(6), 808-827.

Mackenzie, S. B., Lutz, R. J., \& Belch, G. E. (1986). The role of attitude toward the ad as a mediator of advertising effectiveness: A test of competing explanations. Journal of Marketing Research, 23(2), 130-143.

Marta, E. (1997). Parent-adolescent interactions and psychosocial risk in adolescents: An analysis of communication, support and gender. Journal of Adolescence, 20(5), 473-487.

Miller, K. I. (2007). Compassionate communication in the workplace: Exploring processes of noticing, connecting and responding. Journal of Applied Communication Research, 35(3), 223-245.

Shellenbarger, S. (2006, September 21). New directions: Fewer parents encourage kids to follow in their career footsteps. The Wall Street Journal. Retrieved from https://www.wsj.com/articles/ SB115880258945769633

Snyder, J. L. (2007). Extending the empathic communication model of burnout: A search for alternative ways to reduce caregiver burnout (Doctoral dissertation). University of Connecticut, Storrs, CT.

Snyder, J. L., \& Cistulli, M. D. (2009). Can providing comfort to clients prevent caregiver burnout? A field study of human-service workers' compassionate communication. Florida Communication Journal, 37, 73-91.

Solomon, R. C. (1998). The moral psychology of business: Care and compassion in the corporation. Business Ethics Quarterly, 8(3), 515-533.

Warshaw, P. R., Sheppard, B. H., \& Hartwick, J. (1983). The intention and self-prediction of goals and behaviors. In R. P. Bagozzi (Ed.), Advances in communication and marketing research. Greenwich, CT: JAI 